\title{
Correspondencia del Padre Alberto Hurtado C., S.J., relacionada con la fundación de la Facultad de Teología de la Pontificia Universidad Católica(*)
}

\section{PRESENTACIÓN}

A continuación se ofrece una serie de 19 cartas, que permanecían en su mayoría inéditas, que permiten un nuevo acceso tanto a la rica personalidad del Padre Alberto Hurtado, s.j., y a su decisiva participación en la fundación de nuestra Facultad, como a las fuentes que revelan el "espíritu fundacional” de nuestra Facultad de Teología. El artículo publicado más arriba describe las circunstancias de la creación de una facultad de teología en Chile; estos documentos permiten que el lector se informe de primera mano sobre los pormenores y las motivaciones que impulsaron la fundación de nuestra Facultad.

Las cartas escritas por Alberto Hurtado están dirigidas mayoritariamente al Rector de la Universida Católica, Mons. Carlos Casanueva; al Rector del Seminario de Santiago, don Juan Subercaseaux; a su superior en Chile, el P. José Llussá, s.j., y a Manuel Larraín, su gran amigo y Vicerrector de la Universidad. Las demás están dirigidas al P. Hurtado, con excepción de la última, que es una carta de Manuel Larraín a don Carlos Casanueva, que si bien solo menciona de pasada a Alberto Hurtado, es útil su publicación porque expresa el "espíritu fundacional" de nuestra Facultad. Las transcripciones de las cartas han sido realizadas por Jaime Castellón C., s.j., y Sergio Henríquez R., a quienes van nuestros agradecimientos.

\section{CARTA DEL PADRE ALBERTO HURTADO, S.J., A MONSEÑOR JUAN SUBERCASEAUX, RECTOR DEL SEMINARIO DE SANTIAGO Y VICE- RRECTOR DE LA UNIVERSIDAD CATÓLICA}

Lovaina, 17 de Abril de 1934

Monseñor Doctor Juan Subercaseaux, Roma.

Respetado y querido Monseñor:

He de comenzar por pedirle excusas por el retardo en cumplir el encargo que usted tuvo la bondad de hacerme. Pero, por una parte, la preparación de mis exáme-

(*) La investigación y presentación de esta correspondencia, en su mayoría inédita, es obra del Pbro. Samuel Fernández, Profesor de la Facultad de Teología. 
nes de Licencia en Pedagogía y de Licencia en Teología, el aislamiento a que me he recluido por esta causa, y, por otra parte, el deseo de consultar personas competentes antes de responderle, han sido la causa de mi tardanza.

El parecer unánime de todos aquellos a quienes he consultado sobre las ventajas de adoptar el Seminario de Santiago el nuevo plan de estudios eclesiásticos ha sido el de que no les parece que por ahora pueda pensarse en ello, idea con la cual estoy perfectamente de acuerdo.

Las razones que motivan esta manera de pensar son, entre otras, las siguientes. El nuevo plan supone, en primer lugar, sacrificios enormes de personal docente: en nuestro escolasticado de Lovaina, que lo ha adoptado, serán necesarios, según me decía el Padre Rector, veinte profesores para la Teología y de doce a quince para la Filosofía, si se quiere realizar integralmente. El espíritu de la Constitución parece ser el de que un profesor no tenga más de una asignatura y pueda al propio tiempo dirigir los trabajos de investigación personal de sus alumnos. ¡Y cuántas son las nuevas asignaturas! y ¡cuán divididas las supone la Constitución! ¿Podremos nosotros pensar en reunir un número de hombres tan considerable, consagrados exclusivamente a la vida de estudio?

Por otra parte, el nuevo plan está orientado exclusivamente a la formación de los Licenciados y Doctores, no al gran número de alumnos que se preparan únicamente para hacer buenos estudios eclesiásticos que los capaciten para ejercer dignamente sus ministerios. En la Universidad de Lovaina, facultad de Teología, no creo que sean más de doce los estudiantes que siguen estos estudios; y esto en un país de tanto clero como Bélgica. Un sacrificio enorme de profesores para un reducido número de alumnos. Donde hay personal suficiente es de todo punto necesario que se acometa esta empresa de tanta gloria de Dios, y tan necesaria para el progreso de la ciencia eclesiástica, pero donde esto falta... Porque no puede pensarse en hacer extensivo el nuevo plan al gran número de los teólogos. Sería darles una armadura de Goliat a pastores como David, que les haría más daño que provecho. La formación enciclopédica, que supone el nuevo plan, está muy bien para aquellos que han de continuar una vida de estudios serios e intensos, pero no así para los que han de dedicarse a la vida de ministerios. Este recargo de materias distraería la atención del Dogma y la Moral, que han de ser la base de la formación ordinaria de un sacerdote, junto con la Sagrada Escritura, Ascética, Patrística. ¿No le parece que estas materias rumiadas, profundizadas, sentidas internamente, consideradas en sus relaciones con el apostolado moderno han de llevarse la preferencia en la formación de la mayoría?

En tercer lugar, la aplicación seria del nuevo plan supone medios materiales de bibliotecas, revistas, etc., que no sé hasta dónde estén a nuestro alcance.

Si bien la aplicación integral del nuevo plan me parece difícil, creo que habría grandes ventajas en aprovecharse de muchos de los medios que recomienda. Entre las finalidades que claramente persigue la nueva Constitución, una de las principales me parece ser la preparación al trabajo personal, a la investigación científica. Es claramente una reacción contra el sistema de manuales aprendidos de memoria; y contra el hecho de que la ciencia teológica esté como monopolizada por los protestantes o racionalistas, sobre todo en el terreno de la Sagrada Escritura y Patrística. Desarrollar en forma personal un tema de teología, filosofía, filosofía religiosa, ascética, pedagogía, cuestiones sociales, música sagrada, arte cristiano, etc., según 
las inclinaciones, en forma de artículo y aun con miras a la publicación me parece algo sumamente útil. Este trabajo despierta vocaciones de hombres de estudio, interesa, desarrolla el espíritu de investigación, fomenta el gusto literario, mejora el estilo, pone en contacto con las fuentes teológicas o de las respectivas materias, crea una mentalidad. Para ser realizado con fruto ha de ser dirigido por un profesor competente, desarrollado en un "seminario" y ayudado por abundancia de materiales. Yo creo que este es uno de los puntos característicos de la nueva constitución de estudios. Por mi propia experiencia y la de mis compañeros me parece que esta orientación es sumamente provechosa. Si se la quiere realizar plenamente supone toda una adaptación del plan de estudios. Yo no conozco el del Seminario de Santiago, pero en todo caso supone que se dan bastante tiempo al trabajo personal y que por tanto las clases y la preparación de las lecciones no lo consumen todo. Supone también que puede hacerse confianza a los alumnos que sabrán aprovecharse del tiempo que se les da. Al menos la gente más inteligente, y al propio tiempo serios y trabajadores, pueden aprovechar mucho por este camino.

Para terminar este punto de la adaptación del nuevo plan al Seminario, le diré que según he oído deben ser muy pocos los que lo han adoptado. Yo solo he oído del gran seminario de Milán, y creo que el de Buenos Aires. Me dicen que ninguno de los seminarios belgas lo ha adoptado.

El otro punto de que me habló, Monseñor, la formación de una facultad de teología en la Universidad Católica, ha parecido a todos los que he hablado más viable. En primer lugar, si se organiza como la de la Universidad de Lovaina, que supone que los que a ella vienen han hecho ya tres años de seminario, exige naturalmente mucho menos personal. En Lovaina los estudios son excesivamente largos, pues, para sacar el grado de Maestro en Teología exige seis años de facultad (más los tres de seminario); y, con todo, el número de profesores, si se exceptúan los de lenguas, no es más que de unos ocho. En Chile, pues, quizás podría comenzarse con unos tres o cuatro al menos. Los alumnos habrían de ser muy poco numerosos y escogidos: los futuros profesores del Seminario y órdenes religiosas.

Una facultad de Teología en la Universidad, a más de completar y coronar los estudios universitarios, nos permitiría tener en Chile un grupito, todo lo reducido que se quiera, pero de mucha competencia en materia de estudios religiosos. A ellos podría acudirse para pedir orientación en los problemas que cada vez más agudos se irán presentando entre nosotros de filosofía religiosa, teología, etc. ¿No sería esta una solución para combinar los estudios fundamentales, tradicionales, sólidos que habrían de darse a la mayor parte de los seminaristas, con los estudios de carácter más profundo, más moderno, necesarios para el apostolado intelectual en Chile? Yo creo que entre nosotros hay necesidad de unos cuantos hombres capaces de poder afrontar un apostolado con hombres como los profesores del Pedagógico y Universidad de Chile, con los cuales tenemos tan pocos puntos de contacto por nuestra formación general.

Cuando tenga el gusto de verle en Chile conversaremos largo sobre esto, pues tengo muchos deseos de saber lo que usted piensa sobre estos puntos, y entre tanto aprovecho la ocasión para ponerme nuevamente a sus órdenes por si en algo puedo serle útil, lo que será para mí un gran gusto. Me permito enviarle un libro que acaba de salir cuyo autor es el Padre [Joseph] de Ghellinck, a quien usted tal vez conoce, 
sobre los ejercicios prácticos de la nueva institución de los "seminarios" recomendados por la Constitución de estudios.

Aprovecho también esta ocasión para agradecerle, Monseñor, su visita a Lovaina, que hemos comentado con tanto gusto con el Padre [Francisco] Delpiano. Reciba de parte de ambos un saludo respetuoso y lleno de cariño. En unión de oraciones.

Alberto Hurtado C., s.j.

\section{CARTA DEL PADRE ALBERTO HURTADO, S.J., A MONSEÑOR JUAN SUBERCASEAUX, RECTOR DEL SEMINARIO DE SANTIAGO Y VICE- RRECTOR DE LA UNIVERSIDAD CATÓLICA}

Lovaina, 29 de Mayo de 1934

Monseñor Juan Subercaseaux, Roma.

Respetado y querido Monseñor:

Aprovechando una interrupción entre dos series de exámenes, los de Teología, que gracias a Dios acabo de terminar, y los de Pedagogía en la Universidad, que voy a comenzar, escribo cuatro letras a Monseñor para agradecerle su carta tan interesante, y sobre todo para felicitarle de todo corazón por el rumbo que ha dado al asunto de la Facultad de Teología. Dios quiera que esta sea pronto una realidad. Dios ha de bendecir una obra que está llamada a ser el coronamiento de la obra católica que está realizando en Chile la Universidad.

El Padre de Ghellink, a quien impuse de la carta, me insistía únicamente en un punto, a saber, que el número de cursos comunes con el Seminario sea el menor posible, para que los estudios de la Facultad sean verdaderamente universitarios; que aunque fuesen menos los profesores, sean estos tales que den y mantengan el tono de Facultad. Me tomo, Monseñor, la libertad de transmitirle esta opinión, seguro de que usted tendrá gusto en conocerla.

Espero que haya recibido el librito del Padre de Ghellinck, que no le había enviado antes, pues quería estar seguro que usted estaba en Roma. Me permito rogarle quiera aceptar este librito como un recuerdo de su paso por Lovaina.

Se me ocurría proponerle, Monseñor, si no podríamos hacer algo por entrar en contacto con los libreros para obtener en mejores condiciones los libros y revistas, tanto más cuanto que si se crea la Facultad de Teología, será necesario dotarla de ciertas publicaciones modernas. Yo creo que se pueden obtener ventajas considerables. Este punto material, con ser el más desagradable, es, por desgracia, tan importante, dados los escasos recursos de que disponemos en Chile para estas grandes obras que casi no cuentan más que con la Providencia. Así, últimamente he debido entrar en relaciones con la casa editora de la Teología de Van Noort, excelente como libro de texto, pero bastante caro, y me ha prometido un $20 \%$ de rebaja. Para los breviarios obtenemos en casa rebajas de los editores que llegan al $33 \%$ en algunos casos; para las revistas obtenemos muchos intercambios. Este trabajo me parece muy importante, lástima que supone bastante tiempo. Yo por el momento estoy con un gran recargo de trabajo y no puedo ofrecerme a ayudarle 
mucho, pero quizás después de mi tercera probación pudiese hacer algo, si a usted le parece interesante.

En todo caso, Monseñor, dentro de mis escasos recursos, ya sabe que me tiene del todo a sus órdenes.

Le ruego que reciba nuevamente mis felicitaciones más sinceras por el proyecto que ha emprendido y que no me olvide en sus S.S.

Ínfimo siervo en Cristo,

Alberto Hurtado C., s.j.

\section{CARTA DEL PADRE ALBERTO HURTADO, S.J., AL PADRE VICE- PROVINCIAL DE LA COMPAÑIÍA DE JESÚS, PADRE JOSÉ LLUSSÁ, S.J.}

Lovaina, 15 de agosto de 1934

Amadísimo en Cristo Reverendo Padre Vice Provincial:

Me permito escribir a Vuestra Reverencia por aéreo para informarle sobre un asunto importante y urgente. Hace unos pocos días he recibido una carta por aéreo de Manuel Larraín, Vice Rector de la Universidad Católica, diciéndome que la Santa Sede ha urgido a la Universidad a comenzar pronto la Facultad de Teología. Que comenzarán el año próximo, y me encarga que oficiosamente le informe sobre cinco profesores que necesitan para la Facultad, que los busque, les proponga la situación, y sin compromiso avise a la Universidad, la que sobre estos antecedentes cerraría contrato. Han de ser doctores en Teología, eminentes en ciencia, con obligación de dar su curso y algunas conferencias de extensión. Evidentemente hombres de sólida piedad. La Universidad les pagaría el viaje de ida y vuelta, casa y comida, y mil pesos chilenos (entiendo que por mes).

El Padre Rector de Lovaina [Janssens], a quien expuse el asunto, me aprobó plenamente el que hiciera las gestiones necesarias para cumplir el encargo de la Universidad y me insinuó que creía que la mejor solución era que una Orden religiosa se encargase de la Facultad, porque esto daba mayores garantías de éxito, más unidad y una cabeza responsable. Me insinuó las posibilidades que veía para que los Benedictinos o Dominicos se hiciesen cargo, lo que no le parecía fácil. Me preguntó si la Universidad desearía el que la Compañía se hiciese cargo, y si no sería falta de delicadeza de mi parte el proponerlo habiéndoseme encargado el que buscase profesores. Yo le he respondido que la Universidad lo miraría con buenos ojos, y que creo que no lo han pedido por creer que la petición no tendría éxito. Me dijo que en caso que la Compañía se decidiese a aceptar esta obra él creía que de Bélgica, de España -pidiéndolo así el Padre General- se podría obtener el número de sujetos necesario, y aun me indicó algunos nombres de Padres belgas.

Yo escribí confidencialmente al Padre [José] Martí, Secretario, a quien conozco muy bien, y le remití la carta de Manuel para que me indicase si había alguna posibilidad de éxito en transmitir yo mi encargo a Vuestra Reverencia, para que Vuestra Reverencia lo considerase, o si parecía tan claramente imposible que no valía siquiera la pena dar este paso. Me contesta diciendo que el asunto es de mucha importancia, y que después de haber [él] consultado al Padre Asistente [considera que] lo mejor que 
puedo hacer es exponerlo a Vuestra Reverencia. Esto es lo que me permito hacer ahora, exponerle simplemente la petición que he recibido y sugerirle, o mejor, transmitirle esta sugestión del Padre Rector de Lovaina, para que Vuestra Reverencia pueda considerarla si es que merece la pena. Con mi gestión ante el Padre Martí no he procurado en manera alguna iniciar una proposición, ni gestión alguna, sino informarme únicamente sobre la posibilidad de informar a Vuestra Reverencia sobre este asunto, ya que su solución es urgente, pues el nuevo curso habría de comenzar a funcionar el año próximo. El Padre Martí es demasiado prudente para darle mayor importancia a mi carta y me lo hace constar así en su respuesta.

Al mismo tiempo he estado haciendo gestiones para ver si sería posible obtener profesores sacerdotes seculares. Las he hecho en Lovaina, y he escrito a un profesor de Comillas y de la Gregoriana; otro Padre ha escrito a un profesor del Instituto Católico de París. Hasta aquí las respuestas son muy pesimistas, no porque estimen que las condiciones que ofrece la Universidad sean malas, sino porque no hay doctores en teología disponibles, no ya con las condiciones eximias que son de requerir, pero ni siquiera sujetos que fuesen capaces de ser profesores. Fuera de Roma, por lo menos, el número de sacerdotes que hacen los estudios superiores de teología para el doctorado, es muy reducido; lo hacen por cuenta del Obispo y en vista de ocupar inmediatamente una cátedra en el Seminario o Universidad. Sobre esto escribiré más largo a Manuel apenas tenga datos más concretos y completos. Yo continúo haciendo todas las gestiones como si las cátedras fuesen a ser ocupadas por sacerdotes seculares o regulares de otras órdenes.

Si no fuese posible hacerse cargo de la Facultad como tal, ¿no podría aceptarse alguna o algunas clases? Si a Vuestra Reverencia le parece aceptable la idea y lo desea así, yo procuraría enviarle algunos nombres de Padres que con menor dificultad podrían obtenerse.

Perdone, Padre, mi atrevimiento y que me meta en camisas de once varas... pero me ha parecido que no podía quitarle el cuerpo a un asunto que me parece de mucha gloria de Dios y que, aunque no estoy del todo, id est de ninguna manera, capacitado para arreglar, podría con todo prestar algún buen servicio como intermediario por las condiciones en que estoy, vivir en Lovaina, etc.

Y pongo punto para no recargar demasiado el sobre y no doblar la tarifa. Por la misma razón me permito incluirle unas líneas para Manuel Larraín. En los S.S. de Vuestra Reverencia mucho me encomiendo. Ínfimo hijo en Cristo.

Alberto Hurtado C., s.j.

\section{CARTA DEL PADRE ALBERTO HURTADO, S.J. AL PADRE MANUEL LARRAÍN E., VICERRECTOR DE LA PONTIFICIA UNIVERSIDAD CATÓLICA DE CHILE}

Lovaina, 7 de septiembre de 1934

Mi querido Manuel:

Te voy a dar cuenta de las gestiones que he hecho para cumplir tu encargo con respecto a la Facultad de Teología. Primero te diré a quiénes me he dirigido para 
evitarte que hagas inútilmente gestiones ante ellos. Rectores de las Universidades de Lovaina, Milán (Sacro Cuore), Comillas, Gregoriana (ex Rector, Padre Willaert y Padre P. Lazzarini), Bíblico, Seminario de Maynooth (Irlanda: gran Seminario Nacional). He escrito a varios para que tanteen el terreno en París: Padre [Jules de] Lebreton, Padre [Paul] Dudon, Padre Vernay; Strasburgo, Presbítero van Steenberghe; Innsbruck, Padres [Francisco] Delpiano y [José A.] Gómez; Padres Provinciales Jesuitas de Bélgica, Castilla y Toledo; Padres Dominicos de París; Padres Franciscanos de Bélgica (walones) y muchos profesores de la Universidad de Lovaina y Padres jesuitas de distintos países residentes en Lovaina. En la semana próxima iré a Valkenburg para ver al Rector de los Padres españoles de Aragón, conversar con el Rector del gran teologado alemán, y llegaré hasta Nimega [Holanda] para ver al Rector de la Facultad de Teología de la Universidad Católica, que ha tenido que batírselas como nosotros. Por vía ordinaria te enviaré una serie de cartas recibidas para que veas cómo respiran.

De todas estas diligencias se desprenden las siguientes posibilidades:

$1^{\circ}$ ) El sacerdote L[ouis] Jadin, director efectivo del Diccionario de Historia Eclesiástica de la Universidad de Lovaina, que trabaja en los archivos de la misma Universidad y que probablemente entrará como profesor a la Universidad de Lovaina, aceptaría ir a Chile por algunos años, pero no desearía interrumpir sus trabajos científicos en Lovaina y Roma y, al menos por los primeros años, debería volver a Europa desde fines de Octubre hasta Abril. En caso que esta solución sea posible, desearía saber si la Universidad pagaría sus viajes de ida y vuelta y en qué condiciones entraría. Su materia es la Historia Eclesiástica. Hombre bien formado, me ha sido muy recomendado. Doctor por Roma y Lovaina.

$2^{\circ}$ ) El sacerdote Cottiau de Lieja, no ve imposible el ir y deja la solución en manos del Obispo de Lieja. Iré a ver al Obispo la semana próxima; he sido recomendado a Monseñor por el Padre Provincial Belga. Su materia es la Historia Eclesiástica, y creo que podría tomar la Fundamental o Dogma insistiendo sobre todo en el aspecto histórico del dogma y evolución dogmática.

$3^{\circ}$ ) El Padre [Jules de] Lebreton (profesor del Instituto Católico de París, autor de Les origines du dogme de la Trinité; La vie et l'enseignement de Notre Seigneur) me recomienda por medio del Padre [Joseph] de Ghellinck al sacerdote Froideraux, de París, que está destinado a ser sucesor del Padre Lebreton en París. Me dice que cree posible que pueda ir. Le he escrito, pero aún no recibo respuesta. El Padre Lebreton pide se guarde secreto sobre su recomendación.

$4^{\circ}$ ) Tengo dos nombres de dos profesores que me han sido muy recomendados como canonistas, Doctores por Lovaina; uno de ellos es el candidato del Profesor de Lovaina para sucederle en su cátedra. Aún no tengo respuesta.

$5^{\circ}$ ) El Padre [Joaquín] Salaberry, profesor de la Gregoriana y de Comillas, está haciendo gestiones entre antiguos alumnos de Comillas que reúnan las condiciones. Aún no me comunica su resultado, pero se mueve. Me dice que en Buenos Aires reside el señor López Moure, Doctor en Teología por Comillas, uno de los mejores alumnos que pasaron por esa Universidad. Ocupa en Buenos Aires el cargo de Ecónomo. Habita en Rodríguez Peña, 834. Te doy sus señas por si crees que vale la pena hacer diligencias. 
$6^{\circ}$ El Padre Provincial jesuita de Bélgica se ha interesado muy de veras, como también el Rector de Lovaina, y harán todo lo posible por ayudar. Profesores ya formados, esto es que estén actuando como profesores, no pueden cedernos por razones de mucho peso. Pero no creen que sea imposible el que puedan ir dos sacerdotes jóvenes, de talento y buena formación. Ahora que uno de ellos por lo menos no creo que pudiese ir antes de dos años, pues ha de hacer su tercera probación y luego un año para el Doctorado. El asunto para ambos es hipotético, pues ha de ser tratado primero en Roma.

$7^{\circ}$ ) Un Padre jesuita muy conocido, autor de libros muy apreciados, me dice que tal vez podría ir él desde Abril a Octubre, pero no podría quedarse más tiempo. Me pide que no diga nada y no dé su nombre para evitar complicaciones antes de haber escrito a Roma. Es un hombre que conoce muy bien la reforma de estudios, director de una revista para eclesiásticos, muy santo varón... En una palabra, yo creo que aunque no fuese más que por seis meses, sobre todo siendo al comienzo de la Facultad, sería muy interesante tenerlo allá porque daría nombre a la Facultad, y podría prestarles muchos servicios. Podría dar un curso de Derecho Canónico, o de Moral, y aun quizás ambos, si falta personal. $\mathrm{Si}$ el asunto te parece viable, dime qué condiciones le podría ofrecer.

$8^{\circ}$ ) En Alemania sería posible contratar profesores y ciertamente de valor, tanto jesuitas como profesores seglares. Me parece injustificado un prejuicio general contra todos los alemanes, sobre todo que podrían ejercer un apostolado intelectual en el terreno no solo de la teología, sino también de la Filosofía, pues los idealistas alemanes han hecho tanto daño en nuestro Pedagógico. Dime si podría pensarse en ellos. Hay gente seria, trabajadora, y por la gran crisis alemana y la situación religiosa actual, es más fácil encontrar alguno por allí.

$\left.9^{\circ}\right)$ De Irlanda espero respuesta del Rector del gran Seminario de Maynooth; de Italia, el Padre Gemelli me da muy pocas esperanzas. Del Bíblico, aún no recibo respuesta del Rector [Padre Agustín Bea], ni de un Padre a quien oficiosamente pedía datos. El Profesor de Sagrada Escritura me parece el más difícil de encontrar, si se desea -como es necesario- un hombre bien formado.

$10^{\circ}$ ) Los Provinciales de Toledo y Castilla no me han dado ninguna esperanza; la semana próxima en mi viaje a Valkenburg, veré si puede esperarse algo de Aragón. El Provincial de los franciscanos walones, que tiene algunos brillantes sujetos, me dice que no puede soñar en ello; un Padre dominico de París, me recomienda que me dirija a su General, pero antes de hacerlo he querido saber qué rumbo general toman las negociaciones y cuál es la solución que ustedes prefieren, pues, un paso en este sentido debería significar algún compromiso. No necesito decirte que a todos los que he escrito o tratado les he repetido que estas gestiones no significan ningún compromiso, sino solamente un cambio de impresiones.

$11^{\circ}$ ) No te disimulo mi impresión de la dificultad de encontrar desde el primer momento algo que satisfaga plenamente y gente que se aclimate o que los Obispos nos cedan por un número apreciable de años. Yo pienso que el ideal sería formar los futuros profesores buscando seminaristas que estén terminando sus estudios o religiosos en iguales condiciones, y esperar dos, tres o cuatro años hasta que hayan terminado sus estudios de Doctorado. Por lo que concierne a la Compañía me parece mucho más fácil; así me lo han insinuado algunos 
superiores. ¿No podría la Universidad pedirlo a los Superiores, Obispos o Provinciales y ofrecerse a pagar una parte por lo menos de sus estudios? ¿No podría esta solución simultanearse con la de contratar unos profesores para el año próximo?

$\left.12^{\circ}\right)$ ¿Has pensado en la necesidad de una buena biblioteca, de recibir revistas...? En Europa se presentan grandes ocasiones. Ojalá me mandaras proyectos de estatutos, reglamentos de la nueva Facultad, etc.

$\left.13^{\circ}\right)$ Te ruego le preguntes a don Carlos [Casanueva] si le parece bien la idea de organizar en la Universidad una exposición de libros modernos de Pedagogía y de material pedagógico. Podría realizarse con motivo de un cursillo o conferencias de Pedagogía. No significaría ningún gasto para la Universidad. Yo procuraría conseguir material gratuitamente (ojalá me enviara una carta autorizándome oficialmente) que serviría para la exposición y luego habría de ser devuelto.

$\left.14^{\circ}\right)$ ¿No podría pensarse en el Padre [Rafael] Román como Profesor de Fundamental? Te ruego que guardes la proposición para ti, y no indiques que viene de mi parte. El Padre está muy bien formado.

Te ruego me contestes a todos estos puntos. Yo parto para Tronchiennes, tercera probación, el 17 de Septiembre. No podré hacer nada antes del $1^{\circ}$ de Noviembre, pues he de hacer el Mes de Ejercicios. Después, el Padre Instructor me lo permitirá tratándose de un asunto tan importante. Si ocurre algo urgente, escribe al Padre [Francisco] Delpiano a Lovaina. Saluda cariñosamente a don Carlos, a Pancho, a don Alfredo y a los tuyos. Espero que tu mamá vaya mejor. Si tienes ocasión de ver al Reverendo Padre Llussá, ojalá le impongas de esta carta, pues me gustaría que estuviera enterado. Recibe un abrazo de tu hermano.

Alberto, s.j.

\section{CARTA DEL PADRE ALBERTO HURTADO, S.J., A MONSEÑOR CARLOS CASANUEVA, RECTOR DE LA PONTIFICIA UNIVERSIDAD CATÓLICA DE CHILE}

Tronchiennes, 27 de septiembre de 1934

Respetado don Carlos:

Mucho le he agradecido su cariñosa carta y lo que me dice de las gestiones que ha hecho por obtenerme la comisión oficial. Dios se lo pague. Le agradecería que, a ser posible, no hiciese intervenir en las negociaciones a mi tío Miguel [Cruchaga], pues creo que ha de ser muy molesto para él.

Viniendo al asunto de la Facultad de Teología le diré:

$1^{\circ}$. Que me parece de todo punto imposible conseguir como profesores estables, por lo menos por un cierto número de años, hombres que tengan ya fama hecha, profesores que tengan autoridad en Europa. Y esto por muchas razones: Primero, porque nada les tienta en Chile 
a) el sueldo que para nosotros es bueno, muy bueno, reducido a moneda europea se convierte en una gota de agua. Un sacerdote en pleno ministerio gana aquí fácilmente 20.000 francos y con facilidad tiene además casa;

b) el atractivo del país, pues es tristísimo constatar todos los días en qué baja estima tienen la América del Sur, y sin distinciones;

c) ni siquiera lo que más podría tentarles, un campo de apostolado, pues tales hombres lo encuentran aquí abundantísimo y... ¡hasta en Bélgica, donde tienen un sacerdote por cada 700 habitantes, se quejan de falta de clero! Por otra parte, tales profesores eminentes están ligados a obras de que no pueden desprenderse; y, aunque esto en absoluto sea posible, los Obispos no los dejan partir. Es descorazonador ver las respuestas que he recibido en abundancia y que cuando todo esto esté terminado le enviaré, negativas tras negativas... Por esto y por otras ventajas acogí con entusiasmo la idea del Padre Rector de Lovaina de proponerle el que una orden religiosa se hiciese cargo de la Facultad. Yo creo que en tal caso no habría más opción que entre los Dominicanos, tal vez Benedictinos y Jesuitas. Por su carta veo que usted no cree posible por el momento pensar en la Compañía. Me temo que iguales razones pesen para excluir a los Dominicanos y Benedictinos. Otra razón en favor de una orden religiosa la veo en la dificultad que tendrán para entenderse sacerdotes de distintos países, sobre todo dado el estado de inquietud y desconfianza que hay en Europa.

$2^{\circ}$. Suponiendo descartada la primera proposición, me he puesto a buscar sacerdotes seculares o regulares que, sin ser hombres de fama ya hecha, puedan serlo dado su talento y buenos estudios, sin descuidar las otras cualidades de un buen sacerdote. Aun esto resulta muy difícil por análogas razones... Por lo menos he recibido varias negativas. Los sacerdotes Froidevaux (presunto sucesor del Padre [Jules de] Lebreton), de Clercq (idem del Canónigo Van Hove, profesor de Derecho Canónico de Lovaina); Padre [Alphonse] Galle, jesuita; Padre Rigaux, franciscano; etc.

$3^{\circ}$. Posibles por el momento: el Presbítero [Louis] Jadin, para la Historia Eclesiástica, cuyas condiciones expuse en carta a Manuel Larraín; un Padre jesuita de mucha autoridad -cuyo nombre aún debo callar- y que iría por seis meses. Podría dar la Moral y Derecho Canónico. Yo creo que sería muy útil aceptar su ida, pues daría prestigio a la Facultad y podría ayudarnos mucho después en todos sentidos. La condición mínima que se le podría ofrecer es que se le paguen todos sus gastos.

El Señor Obispo de Lieja, a quien le pedí nos cediera al Señor Cottiaux, me contestó negativamente, pero me dijo que no tenía inconveniente en cedernos al Presbítero señor Clysters, que podría dar la Moral. Espero pronto su respuesta, pues he escrito al interesado, que es persona de valer y profesor de un Seminario de Lovaina.

El sacerdote Louis de Witte, joven de mucho valer, acepta ir. Podría dar la Dogmática y este año la Fundamental. Yo no me he atrevido a hacer una gestión ante el Cardenal de Malinas, pues me temo con mucho fundamento una negativa. Sería conveniente que me enviase una petición firmada por el Señor Arzobispo de Santiago a su Hermano el Cardenal José Ernesto Van Roey, Arzobispo de Malinas, haciéndole oficialmente la petición que yo transmitiría personalmente. Con el fin de facilitar esta y las otras posibles gestiones ante los Obispos -supuesta la aprobación 
de la Universidad- he escrito a don Luis Eguiguren pidiéndole que me obtenga una carta de presentación y recomendación del Cardenal Secretario de la Congregación de Seminarios. Espero la respuesta del señor Embajador.

$4^{\circ}$. Hoy acabo de recibir respuesta del Padre Joaquín Salaverri, Profesor de la Gregoriana y de Comillas, a quien le había pedido nombres de sacerdotes antiguos alumnos de Comillas. El Padre, hombre de mucho tino y prudencia, se ha puesto en actividad, ha escrito a varios y me dice a propósito de ellos lo siguiente: "Las gestiones con religiosos han resultado infructuosas. He acudido a personas de solvencia; los que han aceptado son todos moralmente intachables y que sienten hasta cariño por el ideal del apostolado científico que significa la Facultad de Teología de la Universidad Católica... Aceptan las condiciones económicas expuestas. Quedan esperando una invitación oficial posible, la cual aceptarían en principio hasta ultimar detalles en contrato con la Dirección de la Universidad:

Muy ilustre señor don Tomás Castrillo, 38 años. Canónigo Lectoral, Prefecto de Estudios y Profesor de Escritura en el Seminario de Coria. Ha escrito bastantes artículos en revistas de Escritura. Doctor en Filosofía y Teología por Comillas. Licenciado en Derecho Canónico por Comillas. Brillante profesor y entusiasta por la idea. Aceptaría la cátedra de Escritura.

Señor don José Centeno (Apartado 22, Astorga (León)), 36 años. Profesor de Teología en el Seminario de Astorga. Doctor por Comillas en Filosofía y Teología. Licenciado en Filosofía y Letras por la Universidad civil. Tiene fama de gran talento. Aceptaría la cátedra de Moral.

Señor don Laureano Pérez Mier (Villanueva 15, 1², Madrid), 30 años. Profesor dos años de Teología Fundamental en Comillas. Doctor por Comillas en Filosofía, Teología y Derecho Canónico. Licenciado en Derecho Civil por la Universidad de Valladolid. Se doctoraría a principios del año próximo. Aceptaría mejor la cátedra de Derecho Canónico. También, a falta de la de Derecho, aceptaría la de Fundamental.

Señor don Enrique de Cabo (Torrelavega, Santander), 35 años. Profesor de Filosofía en el Instituto de Torrelavega hasta el advenimiento de la República. Doctor por Comillas en Filosofía, Teología y Derecho Canónico. Licenciado en Filosofía por la Universidad civil. Aceptaría la cátedra de Teología Fundamental.

Señor don Agustín de la Fuente (Seminario de Corbán, Apartado 39, Santander), 31 años. Coadjutor en una parroquia. Ha sido nombrado recientemente profesor del Seminario de Santander. Doctor por Comillas en Filosofía, Teología y Derecho Canónico. Aceptaría la cátedra de Moral o la de Teología Fundamental.

Señor don Enrique Valcarce (Ponferrada, León), 37 años. Profesor de Religión en el Instituto de Ponferrada hasta la República. Doctor por Comillas en Filosofía, Teología y Derecho Canónico. Licenciado en Historia por la Universidad de Zaragoza. Aceptaría la cátedra de Historia Eclesiástica.

Señor don Jesús López Moure (Rodríguez Peña, 834, Buenos Aires, Argentina). Coadjutor de una Parroquia en la capital de Argentina, donde tiene a su madre. Doctor por Comillas en Filosofía y Teología. Tiene fama de grandísimo talento. Creo que se le podría ofrecer la cátedra de Teología Fundamental o de Moral.

De todos ellos, el señor Valcarce tiene carrera buena en que abunda la nota sobresaliente. Los otros seis tienen todos carrera muy brillante". Hasta aquí la carta del Padre Salaverry. 
Yo he de confesarle que en principio tengo alguna desconfianza de los sacerdotes que no tengan más formación que la de Comillas, pues aunque sea excelente para formar buenos sacerdotes y hasta profesores de Seminarios, ella sola me parece insuficiente para profesores de Universidad. Lo mismo diría de la Gregoriana. No creo que se les haya podido dar suficiente entrenamiento en los métodos de trabajo científico, aunque tengan una base ideológica excelente. Es verdad que varios de estos candidatos, a los dos o tres doctorados por Comillas unen algún título de Universidad oficial que no es de despreciar y que, por lo que concierne a su formación religiosa y valor moral, hay fundado derecho para creer a priori que han de ser muy buenos. Yo creo que es de todo punto necesario cerciorarse previamente del valor de cada uno de los individuos y si por parte de usted no hay dificultad y no la hubiese por parte de mis superiores, haría un viaje rápido a España para ver a cada uno de los interesados que a usted le pareciese digno de ser tomado en consideración. Espero su respuesta.

Yo preferiría, por las razones dichas y por otras varias, que todos los profesores no viniesen del mismo sitio y por eso, aunque fuese más difícil el obtenerlos, no desistiría de continuar haciendo gestiones para obtener dos o tres franceses o belgas. Yo no rechazaría tampoco en principio a los alemanes. Se pueden encontrar muy buenos y tengo una lista larga de candidatos. Pero no hago gestiones ulteriores hasta conocer su opinión definitiva sobre este punto.

$\mathrm{Si}$ acepta el cerrar contrato con alguno, le ruego me especifique las condiciones. Yo estaré en Ejercicios hasta el $1^{\circ}$ de Noviembre. .

Le agradecería tuviese la bondad de dar a conocer esta carta al Padre Llussá. Si quiere tener como profesor algún jesuita, es de todo punto necesario que escriba al Padre General. Lo mismo se diga de los Dominicos. Yo no he querido sondear el terreno porque sería necesario saber si se comprometerían a tomar uno o no (Dominico).

Perdone, don Carlos, estos garabatos. Con cariñosos saludos para Manuel, Pancho, don Alfredo, don Juan Subercaseaux, etc. Le ruego no me olvide en sus S.S. y oraciones. Su ínfimo hijo en Cristo.

Alberto Hurtado C., s.j.

\section{CARTA DEL PADRE ALBERTO HURTADO, S.J., A MONSEÑOR CARLOS CASANUEVA, RECTOR DE LA PONTIFICIA UNIVERSIDAD CATÓLICA DE CHILE}

Tronchiennes, 5 de noviembre de 1934

Respetado y querido don Carlos:

Con alguna pena le escribo desde la cama. Poco después de escribirle a principios de Octubre se nos comunicó que el mes de ejercicios se aplazaba nuevamente hasta Noviembre, por la mala salud del Padre Instructor. No dudé en aprovechar de este tiempo para ultimar mis gestiones, pues ya en Diciembre sería muy tarde, y con el permiso del Reverendo Padre Provincial partí para Francia y España. Hice un viaje rápido, pero muy fatigoso, pues hube de estar unas 120 horas en tren y a la 
vuelta caigo casi en seguida con escarlatina. La fiebre ha pasado, pero me dice el médico que debo de estar incomunicado de un mes y medio a dos meses. Bendito sea Dios. De todo corazón lo bendigo. Esto sí que me va a imposibilitar para continuar personalmente las gestiones comenzadas, pues tengo de enfermería hasta Enero, mes de Ejercicios... Saldré a mediados de Febrero.

Y creo que esto es una Providencia, pues, aun sin contar con este contratiempo, estaba decidido a decirle que me parece de todo punto necesario que venga -ojalá usted- o si no uno de los Vice Rectores, o don Juan [Subercaseaux], o quien usted crea competente para ultimar este asunto:

a) para tratar autorizadamente con los candidatos y los Obispos;

b) para que viendo la realidad se adopte la mejor manera de asegurar la vida de la nueva Facultad (ya le propondré mis planes);

c) para la adquisición de un mínimum de biblioteca moderna y revistas;

d) para economizar en los transportes... de los profesores;

e) porque preveo que las gestiones en Roma pueden ser lentas: don Luis Eguiguren me escribió diciéndome que el Secretario de la Congregación de Seminarios, id est (creo que el Cardenal [Gaetano] Bisletti [Prefecto de la Sagrada Congregación de Seminarios y Universidades] personalmente) le había dicho que las conversaciones tenidas con don Juan Subercaseaux eran puramente oficiosas y que las gestiones oficiales supondrían todo un año por lo menos.

Yo le voy a exponer un resumen el resultado de mis gestiones.

1) Aceptan irse sin condiciones, pueden partir pronto: Canónigo don Tomás Castrillo (Sagrada Escritura); Presbítero don Enrique Valcarce (Historia Eclesiástica); don Enrique de Cabo (Fundamental); José Centeno (Moral), este último tal vez presente algunas exigencias económicas.

2) Con mejoras económicas: don Laureano Pérez Mier (si 2.000 pesos chilenos mensuales). Señores Perea y Salas (si 1.000 pesetas mensuales).

Todos estos sacerdotes son antiguos alumnos de Comillas, con muy buena base filosófica y teológica, de talento, jóvenes, celosos, muy buenos sacerdotes, que serían excelentes profesores de seminarios, pero yo creo que les falta una mirada más amplia sobre sus materias, un estudio en Universidades extranjeras, el conocimiento de las lenguas modernas. Con todo esto serían excelentes. De aquí que yo creo que el ideal sería enviarlos un año por cuenta de la Universidad a distintas Universidades extranjeras, verbi gratia a Munich o Lovaina al de Historia Eclesiástica, a París al de Fundamental, a Lovaina al de Derecho Canónico, a Roma al de Sagradas Escrituras y entre tanto aceptar profesores suplentes de entre los que le propondré. Si no, la formación de la Facultad quedará definitivamente coja y sería gran lástima.

3) El sacerdote Luis de Witte, diócesis de Malinas, Doctor en Teología por Lovaina, joven de unos 30 años, de excelentes disposiciones, modesto, piadoso, se quedaría aun definitivamente. Me ha sido recomendado por sus profesores. No pone condiciones. La única dificultad está en pedir permiso al Cardenal de Malinas. Yo no he tentado el camino. Mejor que sea pedido, como se lo 
decía en mi anterior, por don José Horacio Campillo y por usted. Podría enseñar Fundamental (a falta de D' Herbigny y de Restrepo).

4) El Padre Adhémar d'Alés, s.j., decano hasta este año de la Facultad de Teología del Instituto Católico de París, director del Dictionnaire d'Apologétique, autor de seis o siete obras teológicas, aceptaría ir por un año y explicaría el tratado de Verbo Incarnato, o de Deo Trino, o de Eucaristía, no el de Fundamental, que no ha preparado. Yo pienso que sería una gloria para la nueva Facultad el tenerle y que vale la pena a pesar del anticipo de esta materia, que podría darse en lugar de una materia accesoria. Él está entusiasmado con la idea de ir, el Padre Provincial no tiene dificultad seria. Debería escribir usted al Padre Provincial de París y también a Monseñor [Henri-Marie Alfred] Baudrillart, pues el Padre debe dar algunos cursos en el Instituto Católico de París y debería anticiparlos -y prepararlos- y el Padre Provincial no quiere pasar por encima de Monseñor Baudrillart. El Padre d'Alés pide una respuesta a vuelta de correo: 15 rue Monsieur, París.

Nota Bene. El Padre d'Alés tiene ya 73 años, pero en pleno vigor intelectual; en sus cursos es bastante aburrido, pero yo creo que a pesar de todo sería gran cosa el tenerle.

5) Monseñor Michel d'Herbigny, s.j., ex rector del Instituto Oriental, antiguo profesor de Fundamental, es un posible candidato. Me lo sugirió el Padre Provincial de París. Me han confirmado en ello hombres que lo conocen bien en Bélgica. Caído en desgracia del Santo Padre (según dicen alejado de Roma por presión de Italia y Polonia) tiene orden de no mostrarse mucho; busca en qué ocuparse. Yo le pedí una entrevista, pero [yo] estaba ya en cama el día en que me citó. Sencillo, trabajador, aunque quizás un poco metido... Debería invitársele de Chile.

6) El sacerdote Luis Jadin, Doctor en Teología por Roma y en Historia Eclesiástica por Lovaina. Bien conocido por sus publicaciones en revistas, trabaja en el Dictionnaire d'Histoire Ecclesiastique de Lovaina. Pide poder volver a Europa cuatro meses cada año. El viaje pagado por la Universidad. Buen profesor, celoso, activo, algo metido; temor de que se desparrame mucho.

7) Doctor en Sagrada Escritura por el Bíblico, no es posible soñar; así me lo ha escrito el Padre Rector del Bíblico [Agustín Bea] y lo he visto confirmado en mis gestiones. Hay, con todo, un Licenciado que partiría con gusto, don Jesús Enciso, profesor en Vitoria. Aún no tengo informaciones completas sobre él.

8) Doctor C. De Clercq, por Roma en Derecho Canónico y por Lovaina en Historia Eclesiástica. Buen talento y trabajador. Partiría solo por seis meses: 15 de marzo al 15 de septiembre. Podría tomar la Historia Eclesiástica y el Derecho Canónico. Dando un cursillo intensivo durante un año, si se desea dar un tiempo para la formación de los profesores estables. Creo que se contentaría con viaje ida y vuelta y 1.000 pesos mensuales por las dos clases.

9) Sacerdotes jesuitas que podrían solicitarse al M. Reverendo Padre General y que no parece imposible de obtener: Padre [Juan María] Restrepo, profesor de Fundamental a la Gregoriana; Padre Michel Fábregas, profesor de Moral a la Gregoriana (Roma le prueba muy mal); Padre Antonio Vigo, profesor en el Seminario de Tortosa; Padre Cándido Mazón, hace bienio de Cánones en 
Roma; Padre Tomás López M., hace su tercera probación, hombre listo, pero que necesitaría un añito por lo menos.

10) Al Padre Provincial de Bélgica podría pedírsele por seis meses al Padre [Gustave] Lambert, profesor eminente de Sagrada Escritura (Antiguo Testamento).

11) El sacerdote suizo $M$ [aurice] Zundel, que me ha sido muy recomendado, no parece inabordable (École Layafette. Rue Ch. Lafitte, Neuilly, Paris).

12) Alemanes eminentes es posible obtener.

13) Para el Derecho Canónico me han señalado también un joven mexicano muy bueno que estudió en París y publicó un tratado de Derecho Canónico y entró y salió de la Cartuja de Parma. Habría que escribir al Prior.

Para mí la mejor combinación entre estos candidatos sería: Monseñor d'Herbigny, Fundamental; Padre d'Alés, de Verbo Incarnato; señor de Witte, Historia Eclesiástica; señor de Castrillo, Moral o Sagrada Escritura; Centeno (si los informes son buenos), Sagrada Escritura. El Derecho Canónico quedaría reemplazado este año por el de Verbo Incarnato.

Creo que en Francia, Bélgica y España no se encontrarán fácilmente otros candidatos, pues he recorrido muchos nombres y obtenido ya muchísimos no. Tenía la intención de hacerle la lista, pero desde la cama no resulta.

Ojalá, don Carlos, que venga usted. El asunto vale la pena. En dos meses se desocupa. Yo le daré personalmente todos los datos. Yo me desentiendo pues de este negocio, pues, como usted ve, no puedo continuar, a menos que usted, después de hablar con el Reverendo Padre Llussá, crea que debo continuar a pesar de todo. Es necesario que ultime los contratos quien pueda hacerlo por sí y ante sí, si no, no se acaba nunca, con gran daño y riesgo de no salir nada en limpio.

Joaquín Larraín, Secretario de la Embajada en España, excelente muchacho, está a sus órdenes para lo que se le ofrezca.

Yo me voy a permitir indicarle los gastos de viaje a Francia, España, Anveres, Malinas, Bruselas, Valkenburg y correspondencia, que son alrededor de 2.250 (dos mil doscientos cincuenta) francos belgas. Le agradecería me enviase un giro para abonarlo yo directamente al Procurador en Bruselas, pues él prefiere que le pague directamente para evitar las dificultades del control.

En mi viaje a Francia y España he entrado en relación con los libreros y he obtenido muy importantes reducciones para las adquisiciones de libros que haga la Universidad: en España lo ordinario es un 25\% y en Francia 28\%, lo que es enorme. Algunos libreros me han prometido enviarme obras para la exposición de Pedagogía de que le hablaba.

En cuanto al asunto de la Comisión oficial, si no fuese posible obtenerla remunerada, le agradecería mucho me la obtuviese ad honorem, y ojalá pronto. Ad honorem le será muy fácil a usted y a mí muy útil. En todo caso, que sea misión de estudios pedagógicos.

Me extraña que Manuel no me conteste a la que le escribí yo en Agosto o Septiembre. De usted tampoco he tenido más que una carta. Le digo esto por si se hubiese perdido.

Perdone la letra, el estilo... La he escrito poquito a poco. Ojalá no diga nada de mi enfermedad, pues no hay ningún peligro de gravedad y temo que si llega a oídos de mi mamá se alarme inútilmente. 
Con cariñosos saludos a Manuel, don Juan, Pancho, don Alfredo, etc., reciba todo el respeto y el afecto de su ínfimo hijo en Cristo.

Alberto Hurtado C., s.j.

Por vía ordinaria va un sobre con correspondencia.

P.S. En Barcelona vi al Reverendo Padre General de los Dominicos, quien se mostró complaciente y pidió que le expusiera por escrito el proyecto de Facultad. No ve imposible una colaboración.

\section{CARTA DE MONSEÑOR CARLOS CASANUEVA, RECTOR DE LA PONTIFICIA UNIVERSIDAD CATÓLICA DE CHILE, AL PADRE ALBERTO HURTADO, S.J.}

Santiago, 13 de Noviembre de 1934.

Reverendo Padre Alberto Hurtado Cruchaga, S. J., Lovaina.

Muy querido Alberto:

Conforme a tu última carta entiendo que ya has salido de los Ejercicios de un mes y más santo que nunca.

Muy agradecido, y no tengo palabras cómo expresártelo, estamos a tu admirable diligencia para conseguir los profesores de nuestra Facultad de Teología, que tiene ya su casa propia, magnífico palacio a una cuadra de la Universidad y a cuatro del Seminario, instalada ya con todos sus muebles y enseres necesarios.

Muy interesantes son las proposiciones que nos haces en tu última carta de 27 de Septiembre último, que me llegó muy oportunamente y transmití conforme a tus deseos al Reverendo Padre Llussá, de la que él se mostró, en la contestación que me envió, sumamente complacido de tus gestiones y me dice que te considera por este motivo "muy digno de alabanza" y me agrega que él, por su parte, ha escrito al Reverendísimo Padre General de la Compañía para interesarle lo más posible en favor nuestro y especialmente al Padre Restrepo Jaramillo, que es el que más vivamente deseamos como profesor de Teología Fundamental.

Hice viaje a Buenos Aires con ocasión del Congreso Eucarístico Internacional, que entre paréntesis fue el más estupendo milagro, como después lo ha calificado el Papa, y el homenaje más grandioso que ha recibido Nuestro Señor en el Santísimo Sacramento del Altar; no te entro en detalles porque ya los tendrás; bastaría para ello notar las 107.000 comuniones de niños y la de 200.000 hombres, comenzando por el Presidente de la República, Ministros, Almirantes, Generales y el Ejército, y las 2.000.000 de almas en la procesión de clausura, y las maravillosas conversiones de millares de millares de almas. Mi viaje principalmente obedecía a hablar con el mismo Padre Restrepo Jaramillo y Monseñor Ruffini, Secretario de la Congregación de Seminarios y Universidades, que venían ambos con el Cardenal Legado. Encontré la mejor acogida en ambos, pero subordinada a la aceptación del Reverendísimo Padre General, a quien envió una nota al respecto nuestro Arzobispo y todos los Obispos chilenos; esta elección me interesa sobremanera; haz mucha oración con 
este fin. Espero la respuesta del Reverendísimo Padre General a esta nota para las resoluciones definitivas.

Muy buen efecto nos han hecho algunos de los sujetos de que nos hablas en tu carta que estarían dispuestos a venir; sería preciso conocerlos personalmente para aceptar mejor en un asunto de tanta trascendencia, para lo cual hemos pensado que, llegado el caso, sería necesario tratar con ellos personalmente antes de cerrar el trato definitivo, para lo cual desearía saber si tus superiores te autorizarían para ello y me indicaras la suma de dinero que necesitarías para los viajes y demás gastos, para enviártelos a la brevedad posible. No sería necesario imponerte dicha molestia si el señor Obispo don Alfredo Cifuentes, Visitador Apostólico de los Seminarios de Chile, pudiera ir a Europa antes de Diciembre próximo. Dime también los gastos que hayas hecho, inclusive correo aéreo, etc., para cancelarte dichos gastos.

Importantísima es también la compra de los libros para la Biblioteca de la Facultad y la contratación de las revistas necesarias; de modo que sería muy útil ver algo al respecto e indicarnos nor- ... [la carta está incompleta]

\section{CARTA DE MONSENOR CARLOS CASANUEVA, RECTOR DE LA PONTIFICIA UNIVERSIDAD CATÓLICA DE CHILE, AL PADRE ALBERTO HURTADO, S.J.}

Santiago de Chile, 13 de Diciembre de 1934

Reverendo Padre Alberto Hurtado Cruchaga, Bruselas.

Mi muy querido Alberto:

Tu última carta aérea, fecha 5 de Noviembre, se cruzaría con la que yo te escribía a ti con fecha del 13 de Noviembre, en la que tendrías la respuesta a algunas de tus preguntas, y hace pocos días recibí el paquete de las cartas cambiadas con los candidatos a clases, y que son muy interesantes.

Y con qué pesar me impongo de tu enfermedad, con todas sus consecuencias, pesar tan grande como la inmensa gratitud que te debo por tu empeño tan abnegado, tan inteligente, tan atinado y tan cariñoso, que jamás podré pagarte y solo Dios podrá recompensarte debidamente; después de Dios y de la persona que ha hecho esta fundación, a nadie le deberá esta Facultad tanto como a ti y a los Reverendísimos Padres Provinciales de la Compañía, que te han dado tantas facilidades, mostrándonos con esto tanta benevolencia y valiosa ayuda.

Supongo en tu poder el Decreto del Ministerio de Relaciones Exteriores dándote ad-honorem la comisión del Gobierno de que ahí se trata. Cuenta con que nuestra Universidad te ayudará para los viajes que hayas de hacer para cumplir dicha comisión, en la inteligencia que tú vendrás a desempeñar las clases de Pedagogía de esta Universidad, que son urgentísimas y de inmensa gloria de Dios en las actuales circunstancias, como en otra oportunidad podré explicártelo, y para que vengas a esta Universidad, además, a la pesca milagrosa de almas y vocaciones para la Compañía y la Iglesia, de que te hablo en mi carta anterior. ¡Si vieras qué esperanzas tengo cifradas en ti y cómo ansío la hora de verte con nosotros realizándolas! Hay más campo que nunca, ni comparable con el que teníamos cuando eras estudiante. 
La Acción Católica ha sido una levadura sobrenatural prodigiosa en nuestra juventud universitaria. Y viniendo a nuestro asunto:

1) Por correo aéreo he mandado orden al City Bank, nuestro banco en Nueva York, de entregar a la orden del Reverendo Padre Paul Goethals, de Bruselas, 3.000 francos belgas, por cable, para cancelar los 2.250 francos y el saldo a tu libre disposición, como modestísimo obsequio.

2) Muy interesantes encuentro las propuestas que nos haces y hemos concentrado nuestros empeños para alcanzar al Padre Restrepo Jaramillo como profesor de Fundamental, y a Monseñor M[ichel] D’Herbigny para Fundamental también; y hemos escrito en este sentido a Monseñor Ruffini; y respecto del Padre Restrepo debe estar ya en Roma la petición al Reverendísimo Padre General firmada por el señor Arzobispo y demás Obispos de Chile y el que suscribe. Respecto de Sagradas Escrituras, nos ha parecido el mejor, dadas todas las circunstancias, el señor Jesús Enciso, que conoció Manuel, y manifiesta mucho interés por cartas recibidas de él, en el supuesto que el Padre Réboli, del Colegio Máximo de San Miguel (Buenos Aires) no pudiera hacerlo, y, en último caso, nos decidiríamos por don Tomás Castrillo, y no pasaríamos más allá por ahora. Para los contratos con el Padre Restrepo y Monseñor D'Herbigny he escrito a Luis Eguiguren y para los otros con el Embajador de Chile en el respectivo país, cuando las dudas queden resueltas. De Moral está ya resuelto el problema acá y probablemente de Historia Eclesiástica y demás ramos secundarios. Puedes quedarte tranquilo y atender a tu convalecencia y a tu tercera probación, salvo caso de urgencia, en que acudiríamos de nuevo a ti, como lo hemos convenido acá con el Padre Llussá. Sin embargo, tenme al corriente si tuvieras nuevas noticias que agregar por correo aéreo.

3) Respecto de libros y revistas he rogado a Monseñor Ruffini nos consiga formar los catálogos respectivos de lo más indispensable para la Facultad, en este primer año. Sin embargo, creo que en definitiva tendremos que acudir a ti. Tennos al corriente, también, al respecto.

Con todo cariño y agradecidísimo te abraza y te bendice tu afectísimo capellán, seguro servidor y amigo

Carlos Casanueva O.

Rector de la Universidad Católica de Chile

9. CARTA DEL PADRE ALBERTO HURTADO, S.J., A MONSEÑOR CARLOS CASANUEVA, RECTOR DE LA PONTIFICIA UNIVERSIDAD CATÓLICA DE CHILE

[Enero/Febrero de 1935]

Mi querido don Carlos:

Sólo dos líneas, porque estoy en Ejercicios. El Rector del Instituto Bíblico [Padre Agustín Bea] me escribe dándome los siguientes informes sobre el señor 
Enciso. "Licentiam adeptus est cum laude. Quantum ad ingenia erat inter meliores et in studiis erat semper assiduus et diligens".

Yo creo que convendría escribir directamente a Monseñor d'Herbigny (College Saint Michel, Boulevard Saint Michel, 24, Bruxelles), exponiéndole directamente el asunto, pues él en rigor no depende de nadie.

Yo creo que sería ventajoso para la Universidad llevarse al Señor Louis de Witte, de quien le hablaba, Doctor en Teología por Lovaina (no de Historia), que tiene buena formación científica de Lovaina, excelente en estudios positivos, la mejor en Historia Eclesiástica. Aunque modesto y sin grandes apariencias, me lo han recomendado como de mucho valer y verdaderamente sobrenatural. Podría quedarse definitivamente y se consagraría todo a la formación del clero. Si lo piden, convendría que usted, el Señor Arzobispo y algunos Obispos escribieran al Cardenal Van Roey, Arzobispo de Malinas, de quien depende.

Si quieren una persona de prestigio por un año (id est ocho meses), podría acudirse al Padre d'Alés para cursos de Dogmática.

Estoy siempre a sus órdenes. Un millón de gracias por su generoso obsequio que emplearé en libros que me puedan servir para el trabajo en Chile.

Saludos a Manuel, Pancho, don Alfredo, don Juan, en cuyas oraciones y en las suyas especialmente me encomiendo para aprovecharme en estos Ejercicios.

Ínfimo hijo en Cristo.

Alberto Hurtado C., s.j.

\title{
10. CARTA DE MONSEÑOR CARLOS CASANUEVA, RECTOR DE LA PONTIFICIA UNIVERSIDAD CATÓLICA DE CHILE, AL PADRE ALBERTO HURTADO, S.J.
}

\author{
Santiago, 17 de Abril de 1935 \\ Reverendo Padre Alberto Hurtado Cruchaga, Tronchiennes. \\ Muy querido Alberto:
}

Recibí tu última carta del mes de Marzo y me [ha] extrañado sobremanera lo que me dices respecto de los cuarenta y dos mil francos belgas remitidos de acá a tu nombre y a tu orden sobre el Banco de Bruselas, con fecha 10 de Enero del presente año. El dicho Banco de Bruselas se halla situado en la rue Regence $\mathrm{N}^{\circ} 2$, y nos envió su acuse de recibo de dichos fondos y se extraña de que no haya comparecido el destinatario a cobrarlos. Están, pues, a tu orden los 42.021 francos belgas, que son 8.404 belgas; ojalá que a la brevedad posible los retires y que obtengas que los entreguen según el valor que tenían el 10 de Enero último, pues he sabido que la moneda belga ha bajado considerablemente por las leyes posteriores. En pocos días más te enviaré una segunda remesa en dólares, desde Nueva York, para los libros que pida el Reverendo Padre Juan María Restrepo Jaramillo, que tenemos la honra de tener como profesor de Teología Fundamental en nuestra Facultad, procurando acogerte a los precios más bajos que puedan conseguirse por los libreros, ya que no podremos dedicar a este objeto más de cien mil pesos chilenos para todo, y los anhelos del Padre no tienen límites y deseo, en cuanto es de mi parte, satisfacerlos. 
La Facultad se inauguró con gran solemnidad el $1^{\circ}$ de Abril y verás, por los recortes de diario que te enviaré por correo ordinario, las grandes proporciones que tuvieron dichas fiestas.

Respecto de los profesores de este año se trajo desde Europa al Reverendo Padre Juan María Restrepo Jaramillo, profesor de Fundamental de la Gregoriana, y que es un encanto bajo todos puntos de vista; al Presbítero Doctor don Juan Stelzenberger, profesor de Teología Moral de la Universidad de Würzburg, con óptimas recomendaciones, notables obras y dignísimo bajo todos conceptos; y al Reverendo Padre Rudolfo Arbesmann, Agustino, como profesor de Historia Eclesiástica, Griego Bíblico y Arqueología, hombre también admirable bajo todo punto de vista. Por la negativa de los señores Enciso y Castrillo a venirse, se nombró profesor de Sagrada Escritura al Presbítero don Daniel Iglesias, Licenciado del Instituto Bíblico de Roma y Doctor en Teología y profesor de nuestro Seminario. Las demás cátedras se proveyeron por profesores de acá, a saber: Presbítero don Eduardo Escudero Otárola, Doctor en Teología de la Gregoriana y profesor del Seminario de aquí, que fue nombrado Decano por la Santa Sede, y Manuel Larraín en Liturgia; fue nombrado Sub-Decano el Reverendo Padre Restrepo y Secretario el Presbítero don Rigoberto Ramírez, Doctor en Teología de la Gregoriana.

No tendrán ya opción ni el señor De Witte ni Monseñor D’Herbingny ni ningún otro, por ahora. Un profesor de Teología para el año próximo y uno de Sagrada Escritura para 1937 se pedirán al Reverendísimo Padre General de la Compañía, que con gran bondad se ha ofrecido para ello. No tengo palabras para expresar la extraordinaria bondad y cariñoso interés para la Facultad que nos ha demostrado el Reverendísimo Padre General de la Compañía.

Dime en tu próxima carta cuánto sería lo que necesitarás para cumplir la comisión que te ha dado el Gobierno de Chile y cuyo nombramiento te lo enviamos en copia en mi última carta y que supongo tendrás ya en tu poder. Es entendido que nuestra Universidad te ayudará a dichos gastos y a la adquisición de los libros más importantes que necesites y que no estén en nuestra Biblioteca, siempre que te designen para hacer la clase de Pedagogía en nuestra Universidad y como te lo he manifestado con tan vivo interés en mis cartas anteriores.

Dios te pague una vez más cuanto has hecho por esta Facultad de Teología, que marcha con muy brillante éxito.

Encomiéndanos mucho a Dios en tus oraciones y a tu afectísimo amigo, seguro servidor y capellán, que te abraza y bendice de todo corazón.

Carlos Casanueva O. Rector de la Universidad Católica de Chile. 


\section{CARTA DE MONSEÑOR CARLOS CASANUEVA, RECTOR DE LA PONTIFICIA UNIVERSIDAD CATÓLICA DE CHILE, AL PADRE ALBERTO HURTADO, S.J.}

Santiago, 31 de Mayo de 1935

Reverendo Padre Alberto Hurtado Cruchaga, S. J., Tronchiennes. Querido Alberto:

He recibido ya aviso de Nueva York, datado en esa ciudad el 8 de Mayo último, que se ha enviado, probablemente con esa fecha o después, la suma de tres mil dólares a tu orden a Bruselas a la Oficina del The City Bank of New York, de los cuales te ruego enviar a la Casa Hachette, al recibo de ésta, la suma de 20.000 francos franceses, para abonarlos a la cuenta que está a nombre de don José Manuel Piñera.

De los demás puntos, que son trascendentales, hablaremos en nuestra próxima carta.

Con sentimientos del más sincero aprecio y cariño, te saluda y abraza de todo corazón tu afectísimo

Carlos Casanueva

Rector de la Universidad Católica de Chile

\section{CARTA DE MONSEÑOR CARLOS CASANUEVA, RECTOR DE LA PONTIFICIA UNIVERSIDAD CATÓLICA DE CHILE, AL PADRE ALBERTO HURTADO, S.J.}

Santiago, 12 de Junio de 1935

Reverendo Padre Alberto Hurtado Cruchaga, S. J., Tronchiennes.

Muy querido Alberto:

Por carta aérea de 31 de Mayo último te avisaba el envío de tres mil dólares a tu orden a la oficina del The City Bank of New York en Bruselas, de los cuales te rogaba enviar a la Casa Hachette la suma de 20.000 francos para abonarlos a la cuenta de don José Manuel Piñera; espero que estén en tu poder y hayas dado las órdenes correspondientes junto con los 42.000 francos belgas enviados anteriormente y que has aplicado con muy buen acuerdo a cancelar el dinero anticipado por los Padres belgas para pagar los libros pedidos por el padre Restrepo.

Mucho te agradezco el favor que nos ofreces del Padre Juamvelz.

El saldo de los fondos, canceladas las deudas que haya, ponlo a tu nombre para los diversos encargos que deba hacerte. Entre estos encargos está el de ayudarte a los gastos que te ocasionen los viajes de estudio, rogándote me digas en cuánto los calculas para darte la autorización sobre la cantidad precisa de que puedas disponer. Por lo que se refiere a libros de pedagogía, indícame cuáles serían los más indicados y su costo para ver lo que podemos tener por acá y no gastar inútilmente.

Hablé con el Padre Llussá, Vice Provincial de la Compañía, aquí, sobre tu destinación a la Universidad, pero desgraciadamente se ha limitado ha autorizar para que hagas una clase de Pedagogía General tres veces por semana en la Universidad; aunque esto desconcierta mucho mis planes, que eran de gloria de Dios y del bien de la Compañía, espero que por el camino se arreglarán las cargas. 
Próximamente saldrá ya el prospecto y la "Revista Universitaria" que trata de nuestra Facultad de Teología, que va con la bendición de Dios prosperando maravillosamente, y ahí verás que tu trabajo fue de mucha gloria de Dios. En el Curso Seglar más de 400 personas asisten a las clases del Padre Restrepo y un buen número a las del Padre Valentín Panzarasa. Lo único que me aflige por el momento es el enorme costo de los libros que me piden estos santos varones; para que saques la cuenta, solo la nueva Patrología, que estiman de necesidad absoluta, cuesta más de \$ 100.000; Mansi, "Los Concilios" como \$40.000, y por ese calibre van los demás. De aquí que tenga que proceder con mucha economía con los fonditos acumulados allá, que son por ahora casi nuestra única esperanza para este objeto. Anda viendo por allá qué compras a lance puedas hacer de esas obras.

Respecto al señor de Witte, la Facultad acordó solicitarlo siempre que sea verdaderamente capaz para la enseñanza de todos los Tratados de Dogmática, excepto de Vera Religione y Ecclesia, para lo que están el Padre Restrepo y el señor Escudero; si no ha de ser muy competente para estas clases no nos serviría. Espero, pues, a este respecto tu información precisa antes de hacer la petición formal de nuestro Arzobispo y de la Universidad al Cardenal de Malinas.

Acerca del profesor Wilpert, nada podemos hacer por ahora, pues en nuestra Facultad no tendría cabida y en el Pedagógico me parece por ahora cosa imposible.

Muy agradecido por todos tus servicios, te abraza con todo cariño tu afectísimo amigo, seguro servidor y capellán

Carlos Casanueva O.

Rector de la Universidad Católica de Chile

\section{CARTA DEL PADRE ALBERTO HURTADO, S.J., A MONSEÑOR CARLOS CASANUEVA, RECTOR DE LA PONTIFICIA UNIVERSIDAD CATÓLICA DE CHILE}

Tronchiennes, 14 de Junio de 1935

Mi querido don Carlos:

Hace algunos días recibí su envío de 3.000 dólares que -por consejo de gente experimentada- cambié en francos belgas (= 88.500 francos belgas), pues después de la devaluación, parece una de las monedas más seguras.

Hoy acabo de recibir su carta y hago inmediatamente el envío a la Casa Hachette de París a nombre del señor José Manuel Piñera (20.000 francos franceses).

Yo termino la tercera probación a mediados del mes de Julio; he de terminar mi tesis para el Doctorado en Pedagogía que he de presentar el mes de Octubre; y creo que pasaré unos meses en Alemania, para salir adelante con el alemán y conocer algo del movimiento pedagógico en ese país que marcha a la cabeza de estos estudios. Esto, si no recibo contraorden de mis superiores. Ya le avisaré mi dirección.

Como siempre, del todo a sus órdenes y rogándole que no me olvide en la Santa Misa.

Ínfimo hijo en Cristo,

Alberto Hurtado C., s.j. 


\section{CARTA DEL PADRE ALBERTO HURTADO, S.J., A MONSEÑOR CARLOS CASANUEVA, RECTOR DE LA PONTIFICIA UNIVERSIDAD CATÓLICA DE CHILE}

Tronchiennes, 28 de junio de 1935

Muy respetado y querido don Carlos:

He recibido su carta del 12 y también la del Padre Restrepo del 21 a propósito del señor De Witte. No dudo en repetirle que, según todos los informes que me han dado, es una persona excelente y sería una gran adquisición para la Universidad. Por lo que me dicen las personas que le conocen -sus profesores de Lovainapodría enseñar muy bien la Teología Dogmática. Es un hombre de talento, trabajador, que hizo muy bien sus estudios en Lovaina: obtuvo gran distinción en su examen de doctorado, y la nota de que podía aspirar al grado de Maestro, que se concede a muy pocos.

Todo esto, dada la seriedad con que se hacen los estudios de Teología en la Universidad de Lovaina, son excelentes recomendaciones. Creo que es la Universidad que exige mayor número de años para dar el doctorado; el número de alumnos es muy reducido, precisamente por lo serio de los estudios. La Facultad de Teología publica varias revistas de primera calidad bajo el punto de vista científico; y las tesis de doctorado son ordinariamente muy apreciadas.

Por otra parte, el señor De Witte es un hombre muy celoso, de Dios, que se consagraría en cuerpo y alma a sus alumnos, y que les impresionaría por su criterio sobrenatural, que he tenido ocasión de constatar en las ocasiones que le he tratado. Y yo creo que esto vale más que todo -si va junto a la ciencia, que no le falta-. Por otra parte, es de una familia muy distinguida, bien educado: es hijo del Barón de Witte, el vencedor de la única batalla de caballería que se libró en la guerra europea. Este detalle, en sí no dice nada, pero prueba tal vez que si va a Chile, es movido del deseo de hacer obra apostólica y no movido por otros intereses. Él estaría dispuesto a quedarse aun definitivamente, por cuanto cree que allá encontrará más campo de apostolado. Yo no dudaría un momento en pedirlo, y ojalá que lo hicieran pronto, pues él desea saber a qué atenerse.

Por otra parte, el Padre Restrepo me escribió con fecha 26 de Abril, dándome contraorden a la suya, en que [usted] me decía no pensara más en el señor De Witte, y me encarga que le propusiese la enseñanza del dogma, lo que hice, recibiendo respuesta afirmativa del mismo. Convendría, pues, no hacerle esperar más tiempo. El único reparo que ponía yo con respecto a su persona es que es joven, no ha enseñado todavía la Teología y es de un exterior modesto; no es de esos hombres que se lanzan y suenan muchas campanillas, pero esto mismo no creo que sea una gran desventaja para el fin que se pretende de la formación seria de los futuros doctores.

Respecto a lo que me dice con tanta bondad e insistencia de ayudarme a los gastos de viaje de estudios, le agradezco en el alma su generoso ofrecimiento, pero su aceptación queda condicionada a la voluntad del Reverendo Padre Vice Provincial. Yo creo que los gastos de viaje serán unos 1.800 francos belgas.

Respecto a los libros, yo desearía adquirir algunas enciclopedias y colecciones de pedagogía, verbi gratia, Rollof, Monroe, Watson, Hadbuch der Erziehungwis- 
senshaft publicada en München, la Psicología de Dumas. Yo no creo que estos libros estén en Chile. Su precio no lo conozco, porque habría de comprarlas en anticuariado, pues nuevas son muy caras. Yo creo que en caso que desee usted adquirir alguna de estas obras fundamentales, me podría autorizar hasta una cierta suma y yo vería lo que se puede comprar según las circunstancias. Todo lo que compraría -igualmente hace el Padre Juamvelz para la Teología- es material usado. Los libros nuevos cuestan un ojo de la cara. Yo me voy el 18 de Julio a Londres por mes y medio, para trabajar mi tesis en la biblioteca del British Museum. Yo creo que sería una buena ocasión aprovechar este viaje para comprar los libros, pues en Londres hay muy buenos anticuariados.

Un último punto. Ya hice el depósito de 20.000 francos franceses (casi 40.000 francos belgas) en la casa Hachette de París a la orden del señor José Manuel Piñera. Luego recibí carta de don Jorge Lira Orrego, acompañándome una suya con orden de girarle 14.000 francos franceses para comprar libros en Hachette. ¿Se trata del mismo asunto? ¿O he de girar los 14.000 además de los 20.000? Ojalá me escribiese a vuelta de correo sobre esto. Don Jorge Lira me dice me escribirá de nuevo a mediados de Julio.

No me alargo, porque me está esperando un compañero para ir al correo.

Ínfimo hijo en Cristo,

Alberto Hurtado C., s.j.

\section{CARTA DE MONSEÑOR CARLOS CASANUEVA, RECTOR DE LA PONTIFICIA UNIVERSIDAD CATÓLICA DE CHILE, AL PADRE ALBERTO HURTADO, S.J.}

Santiago, 24 de Julio de 1935

Reverendo Padre Alberto Hurtado Cruchaga, S. J., Londres.

Muy querido Alberto:

Recibí tu aérea con el gusto y el cariño de siempre. Hablé con el Reverendo Padre Llussá, Vice Provincial, y te autoriza para que hagas clases de Pedagogía en la Universidad Católica hasta tres veces a la semana; me dijo que te había escrito al respecto; siento que sea tan limitada la autorización, pero, qué le hemos hacer. Te autorizo por consiguiente, para disponer para los viajes que te sean necesarios para tus estudios y la comisión oficial que tienes para la suma que me indicas de 1.800 francos belgas, que puedes retirar de la suma que está a tu orden en Europa. De los libros que me anotas querría me indicaras, más o menos, la suma necesaria para comprarlos usados y en la forma que tú me indicas, y, en cuanto sea posible, libros de fácil consulta y solo por excepción en alemán o en inglés, salvo que sean de mucha importancia para nosotros los católicos.

Aquí están muy interesados los profesores de Teología por la obra de Mansi y el "Corpus Patrístico" de Berlín y Viena. ¿A qué precios podrían obtenerse estas obras con todos los descuentos y economías del caso? Querría complacerlos, pero me sería imposible si los precios fueran muy cuantiosos; ve en Londres qué obras de Teología podrían obtenerse en los anticuariados. 
Respecto del profesor De Witte, tendría que enseñar Teología Dogmática en el Curso Doctoral y en el seminarístico, y en el próximo año de 1936 le correspondería los tratados de Verbo Incarnato o de Sacramentis in genere, si no fuera el primero; por lo cual conviene que esté preparado en uno y otro.

La persona de él está ya aceptada unánimemente por la Facultad y el Prelado en todo caso. Las condiciones serían las mismas de los otros profesores que han venido de Europa, a saber: el Reverendo Padre Restrepo y el Doctor Stelzenberger, o sea, mil pesos chilenos mensuales, con la exclusividad de sus servicios para la Universidad, salvo las autorizaciones que esta le otorgara, sea para tener capellanías, etc.; además, sus gastos de viaje a Chile, de él y su equipaje. Apenas estemos de acuerdo sobre estos puntos avísamelo para que el señor Arzobispo dirija su solicitud oficial al Excelentísimo Señor Arzobispo de Malinas y allanar todas las dificultades que se presenten, para lo cual contaríamos también con nuestro buenísimo Ministro en esa, don Jorge Valdés Mendeville. Mucho, pues, deseamos todos contar con el señor De Witte, porque tus informes nos han satisfecho plenísimamente.

Respecto de tu consulta final, te contesto: que los 14.000 francos franceses deben deducirse de los 20.000 enviados a Hachette para pagar lo que tiene autorización de comprar don Jorge Lira $\mathrm{O}[$ rrego]; no es pues una orden diferente. Le escribo en este sentido a Jorge Lira para evitar equívocos. Te incluyo el Prospecto y el número de la Revista en que se habla de la inauguración de la Facultad de Teología, por correo ordinario, y una copia del informe que hemos pasado a la Sagrada Congregación de Seminario y Universidad.

Con el mayor cariño te abraza y se encomienda en tus oraciones tu afectísimo amigo, seguro servidor y capellán

Carlos Casanueva

Rector de la Universidad Católica de Chile

\section{CARTA DEL PADRE ALBERTO HURTADO, S.J., A MONSEÑOR CARLOS CASANUEVA, RECTOR DE LA PONTIFICIA UNIVERSIDAD CATÓLICA DE CHILE}

Londres, 13 de agosto de 1935

Muy respetado y querido don Carlos:

He recibido ahora su carta, que contesto al punto para ganar tiempo en el asunto de De Witte, que creo conviene de toda urgencia ultimar cuanto antes. Él acepta enteramente todas estas condiciones, que las había ya aceptado el año pasado cuando le propuse en Octubre como hipotético el ir a Chile; las volvió a aceptar cuando el Padre Restrepo, por encargo suyo, me dijo le hiciese la proposición, respuesta que transmití a usted o al Padre Restrepo. El pobre está intranquilo por saber qué es lo que hay. Hoy acabo de recibir carta de él en que me dice: "Vous m'excuserez si je suis importun mais je me permets de venir vous demander où en sont les gestions ou sujet du Chili. Depuis votre aimable lettre du débout de Mai, je n'ai plus rien appris. Vous comprendrez, j'en suis sûr, que j'aimerais d'être fixé, dans un sens ou dans un autre, car je veux laisser le soin à la Providence d'arranger 
tout et pour les biens des vótres et pour le mien..." Por otra parte el curso escolar terminó aquí hace un mes y va a comenzar el 15 de Septiembre, por tanto es de toda urgencia no perder un minuto, pues será muy difícil de obtenerlo una vez comenzado el nuevo curso. Créame que se lleva una joyita.

Un millón de gracias por su generosa ayuda de 1.800 francos belgas para el viaje de estudios que haré una vez terminada mi tesis, que he de presentar el mes próximo en Lovaina. La estoy trabajando de cabeza en la biblioteca del British, donde tengo todos los elementos. Para ganarme la vida en Londres estoy ayudando a un párroco, lo que me toma algún tiempo, pero me da en cambio la ocasión de hacer algún bien.

En cuanto a los libros de pedagogía, he obtenido bastantes gratis, pero... iqueda mucho por hacer! Yo creo que lo más sencillo es que me autorice para gastar una cierta suma dentro de los módicos recursos de la Universidad. No le doy idea de los precios de los libros, porque si le indico el precio de los libros nuevos, dado nuestro cambio, es para caerse de espaldas: un librito de nada vale 100 pesos... Y los libros que le indicaba, que son solo unas cuantas obras de base, cuestan muchos miles de pesos. Yo creo que lo más sencillo es que me autorice a gastar, por ejemplo, $2.000 \mathrm{o}$ 3.000 pesos, y veré lo que puedo sacar regateando, de ocasión.

Hoy he pasado el día recorriendo librerías de anticuariado. Creo que será de todo punto necesario comprar libros en inglés y alemán para la pedagogía, pues en castellano no hay casi nada (da pena); y en francés, es pura vulgarización. En Lovaina todos los autores que vemos son ingleses. Ojalá encontrara alguna alma buena que se entusiasmara por ayudar a formar una biblioteca de pedagogía, donde pudiéramos reunir libros que sirvieran de base aun para las discusiones en pro de reforma de la enseñanza. Es un punto que tengo muy ante los ojos al buscar libros.

En cuanto a los libros para la Facultad de Teología, el Padre Juanvelz acaba de comprar de ocasión el Mansi, con otros de los que venían indicados en la lista del Padre Restrepo. Creo que la compra global le ha costado unos 45.000 francos belgas, ocasión que los bibliotecarios por aquí han considerado muy favorable. Pagados estos libros, los 20.000 francos franceses a Hachette, descontados los 1.800 francos belgas que me da para viajes, deben quedar en caja unos 20.000 francos belgas. El dinero se va como la sal en el agua a pesar de todo lo que he hecho y ha hecho el Padre Juanvelz, que es un especialista en librerías, conocedor de ocasiones... por ahorrar. A él le pido que le indique el precio probable de las patrologías de Berlín y Viena, pues él puede hacer eso inmensamente mejor que yo. El Decano de la Facultad de Teología de Innsbruck me ha escrito recomendándome varios jóvenes doctores en teología que podrían ir a Chile.

Si le parece que su carta me puede llegar antes del 2 de Septiembre, le agradecería me escribiese a Londres, The Rosary House, 205, Marylebone Rd. London, N.W.,1. Si después, a 11 rue des Récollets, Louvain.

A mediados de Octubre espero partir para Alemania. Yo espero llegar a Chile a principios de Febrero, deseoso de ponerme incondicionalmente a sus órdenes dentro del tiempo que me concedan los superiores. ¡No deje de encomendarme a Dios! Aquí veo con frecuencia a Ignacio Matte, que le recuerda mucho. Un cariñoso saludo a Manuel, Pancho, al Padre Restrepo y ojalá les dijese -perdone don Carlosque he enviado a su nombre varios paquetes de libros para mí.

Ínfimo hijo en Cristo, 


\title{
17. CARTA DE MONSEÑOR CARLOS CASANUEVA, RECTOR DE LA PONTIFICIA UNIVERSIDAD CATÓLICA DE CHILE, AL PADRE ALBERTO HURTADO, S.J.
}

\author{
Santiago, 23 de Agosto de 1935 \\ Reverendo Padre Alberto Hurtado Cruchaga, S. J., Lovaina. \\ Querido Alberto:
}

Por este mismo correo aéreo escribo al señor Presbítero don Luis de Witte comunicándole la aceptación definitiva por nuestra parte como profesor de Teología Dogmática de nuestra Facultad de Teología para el año escolar de 1936, que comienza el $1^{\circ}$ de Abril, y por el mismo correo va también carta aérea del señor Arzobispo al Eminentísimo Cardenal de Malinas, instándole para otorgar el permiso correspondiente al señor de Witte para que pueda venir a Chile a hacerse cargo de dicha cátedra en nuestra Facultad de Teología.

Respecto a los libros de pedagogía, te incluyo dos cheques que suman $£ 37.5$, que me ha entregado Maximiano Errázuriz para que los inviertas en libros de pedagogía, a condición de que queden en la Biblioteca del "Hogar de los Estudiantes", fundación que él ha hecho para los alumnos católicos, de Pedagogía del Estado, pero no quiere que sean libros alemanes, sino más bien franceses o españoles, porque no poseen ni el inglés ni el alemán dichos alumnos, pudiendo naturalmente usarlos tú como los necesites. No prohíbe, sin embargo, que algunos vengan en inglés, pero como excepción; para los ingleses y alemanes dispón hasta de 2.000 francos belgas, con cargo a los fondos nuestros que tienes en tu poder allá. En nuestra Biblioteca no faltan obras de pedagogía, aunque no las más recientes, por esto limita tus compras a éstas.

No te olvides de averiguar los precios más bajos a que pueden obtenerse las ediciones críticas de los Santos Padres de Berlín y Viena de que te hablaba en mi carta anterior. De acuerdo con el Padre Restrepo, limita tus compras a Mansi, para dejar lo más posible para dichas ediciones críticas, que es lo más urgente de todo, pues no existe un solo ejemplar en Chile, y no están autorizados los trabajos que no se hagan a base de éstas.

Mucho te encargo, también, que con mucha prudencia y reserva, te indagues bien de lo que esta haciendo Ignacio Matte por allá y cuál es el estado de sus facultades mentales, de su vida religiosa y moral, porque llegan por acá noticias que me tienen muy intranquilo, pues es nuestro profesor de Fisiología.

La Facultad de Teología sigue muy bien y los cursos de seglares han tenido un éxito inmenso. El Padre Restrepo está encantado y ha pedido al Reverendísimo Padre General que lo deje definitivamente en Chile.

Con todo el cariño de siempre te saluda afectuosamente, te abraza y bendice tu seguro servidor, amigo y capellán, que se encomienda en tus fervorosas oraciones.

Carlos Casanueva

Rector de la Universidad Católica de Chile. 


\section{CARTA DEL PADRE ALBERTO HURTADO, S.J., A MONSEÑOR CARLOS CASANUEVA, RECTOR DE LA PONTIFICIA UNIVERSIDAD CATÓLICA DE CHILE}

Lovaina, 13 de Septiembre de 1935

Monseñor Don Carlos Casanueva O., Santiago.

Muy querido don Carlos:

Recibí su carta, la que enviaba para el Presbítero señor De Witte y el dinero $(37,10 £)$ para comprar libros de pedagogía, más su autorización de invertir 2.000 francos belgas en lo mismo, según las instrucciones dadas.

El señor de Witte ha sido llamado por el cardenal de Malinas, pero ha recibido una negativa: le dice que lo necesita en la Diócesis. Es una lástima; yo creo que podría insistirse por medio de Roma: de la Congregación de Seminarios, o bien por influencia personal, verbi gratia del Padre Restrepo ante el Cardenal Pacelli. El señor de Witte lo siente en el alma, pues deseaba mucho partir a Chile, pero él se somete a la decisión del Cardenal y él no dará paso alguno para retractarla, así es que si no viene una influencia de arriba no hay nada que hacer. Es una alhajita este sacerdote.

Yo no le escribo más largo porque estoy pasando un gran apuro con preparación de mi tesis, que he de presentar en 10 días y que debo aún trabajar mucho. Una vez terminado este asunto le escribiré largo y le daré los datos que me pide sobre compra de libros (patrología Berlinense y Vienense).

Bendiga a su ínfimo hijo en Cristo,

Alberto Hurtado C., s.j.

\section{CARTA DEL PADRE MANUEL LARRAÍN ERRÁZURIZ, VICERRECTOR, A MONSEÑOR CARLOS CASANUEVA, RECTOR DE LA PONTIFICIA UNIVERSIDAD CATÓLICA DE CHILE}

Punta de Tralca, 20 de enero de 1936

Mi querido don Carlos:

No cabe duda que Nuestro Señor vela por la Facultad de Teología. Después de mi última conversación con usted sobre los profesores que faltan, no puedo ocultarle que quedé preocupado. Yo espero mucho de la Facultad; creo que el Sagrado Corazón la ha fundado para efectuar por medio de ella el realzamiento del clero en nuestra patria y América, pero esto exige profesores muy preparados y de mucho espíritu interior, que enseñen no solo a conocer sino a vivir y a hacer vivir el dogma y la moral. El encontrarse dos cátedras de Teología del curso mayor acéfalas me preocupaba. La solución de urgencia que usted me daba no me parecía oportuna, pues no puede exigírsele a Escudero, por más preparado que sea, que haga bien al mismo tiempo dos cursos diversos de dogma. Pero el Sagrado Corazón comienza a solucionar todo. Hablando con Alejandro Huneeus de la Facultad y coincidiendo con él plenamente en el papel formador que deben tener los cursos que ahí se dan, me 
manifestó que era tanta la trascendencia que él les atribuía que estaba dispuesto a tomar un curso en la Facultad. Inmediatamente le pregunté si tomaría el "De Ecclesia”, que es uno de los que falta por proveer, y me contestó que sí. Creo que Alejandro es un profesor ideal; tiene muy buena formación teológica, su doctorado lo rindió con óptima nota, es amigo del estudio y en cuanto al espíritu mejor no hablar, pues usted lo conoce. Él dejaría sus demás clases del Seminario por ésta, que se la tomaría con amor, pues ve en ella un medio poderoso de formación sacerdotal de sus alumnos. Como ve "Dios ha provisto".

En cuanto al otro curso que aún falta por proveer, uno de los dogmas, insisto en creer que no debe ofrecérselo a J. Luis Castro. Este puede hacer bien el curso seminarístico, pero no el doctoral; es Cura [párroco], tiene muchas preocupaciones y no podrá dedicarse como un curso doctoral lo requiere. Creo que se puede tentar con Alberto Hurtado.

Sin embargo, es necesario urgir, pues si se provee a última hora, por la misma urgencia puede nombrarse a uno que no convenza tanto, con el perjuicio evidente para el prestigio de la Facultad.

Usted perdonará, mi querido Don Carlos, esta insistencia, pero mi opinión es que los sacrificios que la Facultad impone exige que ella cumpla plenamente con el fin para el cual el Sagrado Corazón la fundó. Si vamos a seguir con cursos más o menos semejantes a los que hasta aquí se han hecho en Seminarios y Congregaciones no vamos a llenar ese objetivo.

Los estudios eclesiásticos exigen en nuestra patria una doble reforma, mayor profundidad, para lo cual se requieren hombres de ciencia y mucho mayor espíritu, o sea que se vea en ellos no una simple disciplina que termina en un examen, sino la formación plena del espíritu eclesiástico que tiende a vivir y a hacer vivir lo que se estudia. En esta materia hay que repetir la palabra de san Francisco de Sales a Teótimo "desgraciado el conocimiento que no sirve para amar". La Facultad es el medio escogido por Dios para ese fin, pero tiene que llenarlo ampliamente. De otro modo será un cambio de local y poco más. Hay que hacer que los profesores que lleguen a ella lleven un solo ideal para sus alumnos "donec formetur Christus in vobis", (Gal $4,19)$, que no se queden en la letra que mata sino que vayan al espíritu que vivifica.

La crisis que atraviesa nuestro clero proviene, en gran parte, de deficiente formación teológica y sobre todo de ver en los estudios el minimum que puede exigirse para la vida cristiana y no el ideal de perfección a donde debemos tender y llevar a los demás. La Facultad, para que logre su fin, debe radicalmente corregir estos males, y para esto, en lo posible, buscar hombres cuya mentalidad responda a esta idea, que vivan el ramo que enseñan y busquen siempre el aspecto positivo de la vida cristiana. Faltando esto, es fácil que la Facultad se petrifique y no dé con el tiempo lo que el Corazón de Jesús pedía de ella.

Perdone esta larga carta, mi querido Don Carlos, que no es una crítica sino la expresión sincera de mis ideales y temores sobre la Facultad. Puedo repetir con el poeta: "amor mi muove che mi fa parlare" (Dante, Divina Comedia, Infierno II, 72).

Llegarán mañana cinco sacerdotes argentinos de Santa Fe que conviene conozcan la Facultad. Los llevará a verse con usted el Cura de Los Andes, Miguel Cadieux.

Reciba todo el cariño de su hijo afectísimo in Corde Iesu. 